\title{
Public Perception of Nanotechnology
}

\section{Journal Article}

Author(s):

Burri, Regula V.; Bellucci, Sergio

Publication date:

2008

Permanent link:

https://doi.org/10.3929/ethz-b-000013796

Rights / license:

In Copyright - Non-Commercial Use Permitted

Originally published in:

Journal of Nanoparticle Research 10(3), https://doi.org/10.1007/s11051-007-9286-7 


\title{
Public perception of nanotechnology
}

\author{
Regula Valérie Burri · Sergio Bellucci
}

Received: 2 January 2007 / Accepted: 25 July 2007 / Published online: 18 August 2007

(C) Springer Science+Business Media B.V. 2007

\begin{abstract}
While several studies on the public opinion of nanotechnology have pointed to a rather enthusiastic U.S. public, the public uptake of nanotechnology in Europe is more contained. The results of the Swiss publifocus on nanotechnology reveal a pragmatic attitude of citizens toward the emerging technologies, thus confirming what has been identified as a "balanced approach" in the NanoJury UK.
\end{abstract}

Keywords Nanotechnology - Nanoscience · Citizens - Focus groups - Upstream engagement . Public attitudes $\cdot$ Societal implications

\section{Introduction}

In recent years, discourses on science-society interactions have been increasingly pointing to the importance of the public response to and acceptance of emerging technologies. While early discourses in the Public Understanding of Science had diagnosed a lack of scientific literacy among laypeople and identified it as a cause for the public's low support

R. V. Burri $(\square)$

Collegium Helveticum, ETH \& University of Zurich,

Zurich, Switzerland

e-mail: burri@collegium.ethz.ch

S. Bellucci

Swiss Centre for Technology Assessment (TA-Swiss),

Berne, Switzerland of scientific research (Bodmer 1985), recent discourses are not pointing to such a "deficit model" (Wynne 1991; Ziman 1991) but underline the importance of the public's involvement in science policy. According to this understanding, the public should be able to not just understand science but also participate in decisions on further developments of research and future applications at an early stage of R\&D-thus being enabled to participate in an "upstream engagement." 1

The commitments to "upstream" the dialogue between science and the public in processes of technological innovation also mark a shift in public policy discourses (Macnaghten et al. 2005). Governmental authorities are keen to avoid a repetition of the heavy controversies that had accompanied the diffusion of biotechnology. The consensus that the public should be involved in deliberative discussions and assessments of emerging technologies at a much earlier stage of technological developments is a widely shared concern among governmental as well as nongovernmental stakeholders. This is especially the case when emerging technologies might imply unforeseen health and environmental hazards, as

\footnotetext{
1 "Upstream engagement" is a term that has been used by UK researchers (e.g., Wynne 2001; Wilsdon and Willis 2004; Macnaghten et al. 2005; Stilgoe and Wilson 2005; Wilsdon et al. 2005) and promoted in the UK Royal Society's report on nanotechnologies (Royal Society 2004) to underline the need for public engagement at an early stage of scientific development and technological innovation.
} 
several studies by scientists, science organizations, the industry, and NGOs have claimed in regard to nanotechnology (e.g., ETC Group 2003; Swiss Re 2004; Royal Society 2004, Oberdörster et al. 2005).

As a result, several initiatives to discuss nanoscience and its potential risks have been started in different countries. In order to foster an upstream engagement in nanotechnology, citizen juries, consensus conferences, focus groups, and discussion groups have been organized in various places mostly during the year of $2005 .^{2}$ In the fall of 2006, focus groups on nanotechnology were also organized in Switzerland with the aim of exploring the public's attitudes toward the emerging technologies. This article presents the results of the focus group discussions, which confirm what has been called a "balanced approach" in the NanoJury UK (RogersHayden and Pidgeon 2006), and which reveal the public's urge for a nano declaration and for regulatory actions. Furthermore, the discussions showed citizens' high appreciation of science communication and of upstream public engagement in processes of technology assessment.

\section{Background}

The Swiss focus groups on nanotechnology took place in September 2006. They had the form of a socalled publifocus, which is an instrument developed by the Swiss Centre for Technology Assessment (TASwiss) to facilitate public discussion of emerging technologies. The nano-publifocus was intended not only to contribute to increased public awareness and inform further debate, but also to help decision makers in assessing nanotechnologies (TA-Swiss 2006a). It was supported by governmental and scientific institutions and assisted by a supervisory group that consisted of scientists and experts from other fields such as the industry. The citizens were

\footnotetext{
${ }^{2}$ Citizen juries and consensus conferences were held in the United States and the United Kingdom (Madison 2005; Rogers-Hayden and Pidgeon 2006). Several focus groups (or similar discussion groups) were also organized in New Zealand, in the United States, and in the United Kingdom (see Cook and Fairweather 2005; Macoubrie 2005; Kearnes et al. 2006). In addition, stakeholder workshops have been organized, for example, in the United States (Roco and Bainbridge 2005).
}

chosen by a random procedure that had already been applied to other discussion forums of TA-Swiss in earlier years. 10,000 addresses of randomly selected persons had been bought from a marketing company. These persons were asked in a letter if they were willing to participate in the publifocus. 300 persons were interested, and among those around 70 were chosen depending on the criteria age, gender, profession, political activities (if people had declared to be engaged in such), and place of residence. ${ }^{3}$ The selected persons were divided into four groups. An additional group consisted of representatives from different stakeholder groups, ranging from science and the industry to farmers' associations, consumer organizations, and NGOs. Each of the groups met in various Swiss cities in different language regions during half a day each. ${ }^{4}$ The discussions were moderated by a person experienced with discussion groups, and two experts gave short presentations from a scientific and ethical point of view. In contrast to the NanoJury UK, no recommendations were formulated during the meetings, but the discussions were recorded in writing and summed up in a final report (TA-Swiss 2006c). ${ }^{5}$

\section{Briefing materials}

Studies on the public uptake of nanotechnology have mostly found a lack of knowledge and of understanding of the context of nanotechnologies (Waldron et al. 2006), and have revealed a high level of enthusiasm for the potential benefits but little or less concern about possible risks nanotechnologies might engender (Bainbridge 2002; Cobb and Macoubrie 2004; Macoubrie 2006). While some of these studies were large-scale surveys of an uninformed public, Macoubrie (2006) investigated experimental groups whose participants were given briefing information and were presented with various nanotechnology

\footnotetext{
3 The aim of the publifocus, however, was not to "measure" public's attitudes in statistical terms.

4 The cities were Winterthur and Bern (in the Germanspeaking part of Switzerland), Lausanne (in the Frenchspeaking part), and Lugano (in the Italian-speaking region). The meetings took place either in a school or in a conference location of a hotel.

5 The results are taken from this report and from an observation of the discussions during the publifocus.
} 
development scenarios. New informations may or may not change individuals' perceptions of a technology. Macoubrie showed in her study that the briefing information altered individual attitudes from a more neutral to a more positive view of nanotechnologies (p. 232). Nevertheless, she concluded that the concerns of individuals "are not simply attributable to the information with which they were provided" (p. 237).

The participants in the Swiss publifocus on nanotechnology had as well been exposed to briefing materials prior to the discussions. An information brochure on nanotechnologies which was twelve pages in length had been sent them by mail. The brochure was specifically written for the briefing of participants of the publifocus and thus designed to address lay people. It explained in a comprehensive way the state of the art in this research field and pointed to some critical points raised by various international reports (TA-Swiss 2006b). The brochure did neither privilege positive nor potentially negative consequences of nanotechnologies. ${ }^{6}$ The same can be said regards to the short presentations of the experts which during the publifocus presented the state of the art in both risk research and ethical discourses on nanotechnology. The talks were not biased in a positive nor a negative way. The result that the participants of the publifocus perceived nanotechnologies differently suggests that the information brochure and the presentations did not have a determining effect on their perceptions of nanotechnologies. This is supported by Macoubrie's findings whose briefing materials are not described as being enthusiastic; nevertheless the individuals taking part in her study were strongly positive about the potential of nanotechnology even after reading the controversial information materials (p. 234). ${ }^{7}$

\footnotetext{
${ }^{6}$ The information brochure of the Swiss publifocus thus seems to be comparable to the briefing material "condition 1 " in Macoubrie's study which presented basic information and an overview of nanotechnology applications in general (Macoubrie 2006: 224), though the Swiss brochure was more extended.

7 In contrast to Macoubrie's (2006) study, we did not explore the attitudes of participants before they had read the information brochure. Nevertheless, the sources of information and knowledges of laypeople were heterogeneous since a few had heard about nanotechnologies in the media or from colleagues while many had not.
}

\section{A pragmatic attitude toward nanotechnology}

Many participants of the publifocus were confronted with the topic for the first time and were quite concerned when they heard about the risks nanomaterials might imply. Citizens feared that nanoparticles might enter the human body and cross the blood-brain barrier, and they were worried that nanoparticles might accumulate in the environment, or that they might be harmful when being integrated into food. Some people also mentioned that this research might increase a divide between rich and poor countries, and that it might result in the loss of certain jobs.

Despite these concerns, the opportunities that nanotechnology might bring in the future were highly estimated. Citizens hoped that nanomedicine will succeed in curing certain diseases and that nanotechnologies will contribute to finding solutions to solve urgent environmental problems. In addition, citizens mentioned the possibility that developments in nanosciences will create new opportunities on the job market. Future benefits were also seen in improving life quality and making daily life easier. Participants hoped that they will have to clean less when kitchens, bathrooms, and cars will be produced with nano surfaces in the future.

Such examples reveal a rather pragmatic approach that Swiss citizens demonstrated toward nanotechnology. Participants neither feared any pessimistic science fiction visions nor showed a great enthusiasm-thus confirming the results of several studies that have pointed to a more skeptical European public in regard to the potential dangers associated with nanotechnologies (e.g., Royal Society 2004; Gaskell et al. 2005). Overall, participants were rather positive toward nanotechnology, and qualified the opportunities and benefits higher than the potential risks. They thus demonstrated what social researchers Tee Rogers-Hayden and Nick Pidgeon (2006) have called a "balanced approach" to nanotechnologies when reflecting upon the UK's citizen jury on nanotechnology. "The science and business communities," the authors write, "need not fear that engaging the public will solely highlight negative consequences or concerns about risks" (2006: 167). In the Swiss focus groups, participants equally demonstrated such a balanced approach. They did not claim to prevent any further research in the field of nanoscience, or to stop 
government's financial support for research in that field. Quite the contrary: citizens pleaded for ongoing research activities, which should also embrace further research on potential risks.

\section{The call for information and a nano declaration}

Just like other stakeholders, participants in the publifocus have remained aware of the political controversies that had come along with the diffusion of biotechnology. In Switzerland, these debates had resulted in two votes on the future of research in genetic engineering. ${ }^{8}$ While many citizens rejected products associated with green biotechnology, they were not equally critical toward nano products at the time of the publifocus. Some people, for example, stated they were using sportswear made with nanotechnology or had nanomaterials in their household. Others, however, complained that they were possibly using such products without even being aware that they might contain nanoparticles. Most participants thus wanted more information and a better communication on research activities which would inform the public on future developments in nanoscience and technological applications, and provide a better understanding of potential risks. In contrast to the situation that had emerged due to the late public diffusion of scientific knowledge in biotechnology, citizens opted for early science communication on nanotechnology. Furthermore, citizens wanted better product information. Products containing synthetic nanoparticles, many participants stated, should be provided with a declaration that reveals their compounds. This would enable every citizen to make a decision on buying a nano product or not. Citizens in the publifocus thus not just had a point of view as political subjects but as well argued as consumers when pleading for a liberty of choice on the market. Nevertheless, many citizens pleaded for a strict governmental regulation of nanotechnology, for example by opting for a specific law that would regulate the emerging technologies and related products.

\footnotetext{
${ }^{8}$ One of these votes resulted in a moratorium that inhibits the release of genetically modified plants during a 5-year period.
}

\section{Conclusion}

The Swiss focus groups on nanotechnology showed that citizens today, at least in the Swiss context, are neither reluctant toward nanotechnology nor highly enthusiastic facing the potential environmental and health risks the emerging technologies might imply. Nevertheless, citizens hope for economic payoffs through the creation of jobs in the nano industry, and are optimistic in regard to the benefits nanotechnology might bring to innovations in medical treatment, environmental activities, and daily life in the future. Citizens support further research in the field, which should in their view also aim at increasing scientific knowledge on potential risks. Future research, however, should be well communicated to the public, thus enabling citizens to take actions when considered necessary, and to get involved in decision making on regulatory measures. For the time being, many citizens plead for a nano declaration that would indicate the compounds of a product. Participants were arguing for a liberty of choice that would amplify their options as both citizens and consumers. At the same time, many citizens opted for a strict governmental regulation of nanotechnology and related products.

In contrast to the U.S. public, citizens thus revealed a pragmatic attitude and a balanced approach toward nanotechnology. Their quests for sound science and for better information on both research activities and product compounds go along with a pragmatic acceptance of research in nanotechnology, which not only points to the negative consequences but also looks at potential opportunities of nanotechnology in the future. The publifocus also showed that upstreaming public engagement in the deliberation regarding emerging technologies is not only seen as an important policy instrument by government's authorities, but also perceived by citizens as an indispensable tool to participate in technological innovations and their assessment. In the view of TA-Swiss, the public discussions on nanotechnology have to be continued to enable the public deliberation of the emerging technologies.

\section{References}

Bainbridge WS (2002) Public attitudes toward nanotechnology. J Nanoparticle Res 4(6):561-570 
Bodmer WF (1985) Public understanding of science. Report of a Royal Society ad hoc group. The Royal Society, London

Cobb M, Macoubrie J (2004) Public perceptions about nanotechnology: risks, benefits, and trust. J Nanoparticle Res 6(4):395-405

Cook AJ, Fairweather JR (2005) Nanotechnology-ethical and social issues: results from New Zealand focus groups. Research Report no. 281. Canterbury, New Zealand: Lincoln University. URL (consulted 24 June 2006): http://www.lincoln.ac.nz/story_images/ 1330_rr281_s4140.pdf

ETC Group (2003) The big down: atomtech-technologies converging at the nanoscale. ETC Group, Winnipeg, Manitoba, Canada

Gaskell G, Ten Eyck T, Jackson J, Veltri G (2005) Imagining nanotechnology: cultural support for technological innovation in Europe and the United States. Public Underst Sci 14:81-90

Kearnes M, Macnaghten P, Wilsdon J (2006) Governing at the nanoscale: people, policies and emerging technologies. Demos, London

Macnaghten P, Kearnes MB, Wynne B (2005) Nanotechnology, governance, and public deliberation: What role for the social sciences? Sci Commun 27(2):268-291

Macoubrie J (2005) Informed public perceptions of nanotechnology and trust in government. Woodrow Wilson International Center for Scholars, Project on Emerging Nanotechnologies. URL (consulted 26 November 2006): http://www.wilsoncenter.org/index.cfm?topic_id=166192 \&fuseaction=topics.event_summary\&event_id=143410

Macoubrie J (2006) Nanotechnology: public concerns, reasoning and trust in government. Public Underst Sci $15(2): 221-241$

Madison (2005) Report of the Madison area citizen consensus conference on nanotechnology. 24 April. URL (consulted 5 April 2006): http://www.lafollette.wisc.edu/research/ Nano/nanoreport42805.pdf

Oberdörster G, Oberdörster E, Oberdörster J (2005) Nanotoxicology: an emerging discipline evolving from studies of ultrafine particles. Environ Health Perspect 113(7):823839

Roco MC, Bainbridge WS (2005) Societal implications of nanoscience and nanotechnology: maximizing human benefit. J Nanoparticle Res 7:1-13
Rogers-Hayden T, Pidgeon N (2006) Reflecting upon the UK's citizens' jury on nanotechnologies: nanojury UK. Nanotechnol Law Business May/June:167-178

Royal Society (2004) Nanoscience and nanotechnologies: opportunities and uncertainties. RS policy document. Royal Society and Royal Academy of Engineering, London

Stilgoe J, Wilson R (2005) Public engagement with science. Demos, London

Swiss RE (2004) Nanotechnology: small matter-many unknowns. Swiss Reinsurance Company, Zurich

TA-Swiss (2006a) Publifocus Nanotechnologien-Bedeutung für Gesundheit und Umwelt. Projektbeschrieb für die Durchführung eines Dialog-Verfahrens mit Bürgerinnen und Bürgern. Zentrum für Technologiefolgen-Abschätzung beim Schweizerischen Wissenschafts- und Technologierat, Bern

TA-Swiss (2006b) Know your nano! information brochure for publifocus nanotechnology, health and the environment. Center for Technology Assessment at the Swiss Science and Technology Council, Bern

TA-Swiss (2006c) Public reactions to nanotechnology in Switzerland: the findings of the publifocus discussion forum nanotechnology, health and the environment, by Lucienne Rey. Center for Technology Assessment at the Swiss Science and Technology Council, Bern

Waldron AM, Spencer D, Batt CA (2006) The current state of public understanding of nanotechnology. J Nanoparticle Res 8:569-575

Wilsdon J, Willis R (2004) See-through science: Why public engagement needs to move upstream. Demos, London

Wilsdon J, Wynne B, Stilgoe J (2005) The public value of science: or how to ensure that science really matters. Demos, London

Wynne B (1991) Knowledges in context. Sci Technol Human Values 16(1):111-121

Wynne B (2001) Creating public alienation: expert cultures of risk and ethics on GMOs. Sci Cult 10(4):445-481

Ziman J (1991) Public understanding of science. Sci Technol Human Values 16(1):99-105 